\title{
A CATALONIAN PHILOSOPHER: ANTONIO COMELLAS Y CLUET.
}

HE name of Antonio Comellas y Cluet will always
have a distinguished place in the history of philosophy, especially that of Spain, where he was deemed a laborious and illustrious thinker. $\mathrm{He}$ is one of the Spanish thinkers whom I was not able to overtake or discuss in the chapter devoted to "The Philosophy of Spain" in my Studies in European Philosophy (Blackwood, I909), and this paper is devoted entirely to him in supplement of the treatment then made of churchly-scholastic philosophers in Spain during the last century.

Comellas found himself planted in a time in which the negations of positivism had found their way, and the critical effects of Kant had been felt. It was this atmosphere that made him feel the need to consider the possibility of science, and the legitimacy and value of scientific method and procedure. This explains the character of his great work, Introduction to Philosophy, which is no mere propædeutic, as the phrase might suggest, but a critical study of method; of the sources of knowledge; of the criteria of truth; of the motives or reasons of certainty; and of the bases of science, under rigid analysis. I wish to say that, in addition to my own study of the work of Comellas, I have had the advantage of the valuable study of Comellas made by another distinguished Spanish philosopher, Alberto Gómez Izquierdo, in Cultura Española (Madrid, 
1907). Comellas cannot be said to have had the originality to create an entire philosophical system, though a synthetic organization may be claimed for his thought and its discussion of fundamental positions. Some account of these may be of interest, and I shall deal only with those points that seem most essential, making such critical comments as seem to me necessary. He did not found, and scarcely affiliated himself to, a particular school.

I.

It may be well to consider first the position of Comellas on the methodological problem. He makes three stages or periods in the evolution of science. The first of these is that of the real, in which man holds to being or to forces, without as yet having unfolded them. He emerges from this condition through the attractive power of the ideal, and the aspiration for truth. Comellas has, rightly I think, emphasized the emergence of the opposition of fact and ideal-as various thinkers have done since-but we must not lose sense of the slowness of the process in the crispness of the statement. Nor must we overlook, in speaking of the ideal, the retardations due to the slow-footed movements of the positivist spirit in various spheres of scientific knowledge. The second stage is that of the attracting ideal, wherein is seen the activity of human reason in abstraction, generalization, induction, and deduction. In the third stage, we have the synthesis of the real with the ideal. On this hypothesis has Comellas based the formation of science, grouping around it the various questions as to critical method. Totalizations for mind is thus what Comellas derives from the fusion of empiric fact with intellectual working and ideal. It should be observed that the three stages now enumerated form the three divisions of the work.

The position of Comellas as to universal doubt being 
the point of departure in scientific investigation is, that such doubt is a skeptical means to a dogmatic end (p. 33). $\mathrm{He}$ does not think even partial doubt is necessary as an antecedent of investigation. Nobody, he thinks, would contradict the fact that as often as we investigate things, we doubt concerning them. And yet we can, in his view, frequently see that people investigate things without doubt of them, and he gives examples of such cases (pp. 67-69). One of these is the case of trying to demonstrate an accepted truth by new arguments. One thing, I may remark, that cannot be doubted is that we doubt. There is a rational skepticism which is necessary and healthful: there is also an enervating skepticism, which weakens the mind's trust in itself. Whatever scientific knowledge or certainty may have owed to doubt, it should not be so often overlooked how much more it has owed to rational belief-belief, I mean, in those rational, self-evident, necessary principles which make fundamental appeal to our rational insight. It has been said by another distinguished Spanish philosopher, Balmez, that "certainty does not originate in reflection; that it is the spontaneous product of man's nature, in the direct working of his intellectual and sensitive faculties; and that philosophy simply examines the grounds of certainty, while recognizing that those first principles, which are the basis of all evidence, are themselves incapable of proof" (Fundamental Philosophy, Bk. I, Ch. III). But I may add that direct and natural certainty is, to scholastic philosophers, the basis of philosophic certainty, which is of reflective and demonstrative character. For Comellas the certain and the evident are but the support necessary to soaring toward the ideal. But the ideal is not to be sought in the works which our predecessors have left us. To no writer or generation has Deity said, Thine are the treasures of science, gather them according to the measure of thy mind, and they will be the unique patrimony of 
humanity (p. 8I). In this Comellas spoke wisely enough, for no attempts to coordinate all human science, whether those of an Aristotle, an Aquinas, a Descartes, a Leibniz, or a Comte, can have finality, though every one of them must have great value and most helpful function. Comellas quotes interesting passages from Anselm, Albertus Magnus, Aquinas, and Roger Bacon, setting forth the doctrine of progress in science, which is thus not so entirely modern a doctrine as is often supposed (pp. 82-85). Not through our predecessors is the ideal found, but as the result, Comellas thinks, of our own search, with amplitude of thought, personal examination of issues, and scrupulous rigor of observation, taking due account of the workings of reason, and the evolution and conditions of our faculties of knowledge, whether empirical, or abstractive, or deductive (pp. I08-I09). These three moments Comellas treats in this successive order: perception of an object, abstraction, and contemplation of the object abstracted; intuition of its content; and, finally, combination of the content of the object abstracted with empirical fact, wherein consists deduction. All these acts are discussed by Comellas at length, but we have only room for a few observations.

Perception he discusses in its differences as related to the corporeal world, and the phenomena of spirit; the former he refers to sense, the latter to consciousness. In respect of empiricism, he finds the methods of Mill useful. This does not keep Comellas from being independent and critical of Mill, as he is, for example, on induction (pp. 184-194), where he objects to Mill's positivist tendency in eliminating the metaphysical element from deduction, and making all the deductive sciences inductive. I may observe that there is no need to distinguish induction and deduction so sharply as is sometimes done, as they are so closely interrelated; and that critics of Mill like Jevons and Welton recognize the necessity of deduction in respect of the con- 
sequences of the inductive hypothesis as first framed. We can no more dispense with the deductions of I.aplace, Lagrange, and Gauss, than with the great induction of Newton. The fruitful results of induction for knowledge must not obscure for us the splendid scope for intellectual power afforded by deduction, with its expansive effects for knowledge. Infinite being or substance purely spiritual, cannot, Comellas thinks, be direct object of abstraction; it is reached by combination of abstractions. He takes a wide view of intuition, including in it various dialectical processes; and to intuitive power and working, not to inductions based on fact, he attributes the formation of universal principles which are absolute and evident, and forms the most important factors of deductive thought. Ueberweg's Logic has had influence on his view of deduction, and on other matters (as for example, later, at pages 233 and 243). The foregoing matters are discussed at considerable length (pp. I55-I94), but cannot here be further pursued.

II.

Then Comellas dealt also with the critical problem. $\mathrm{He}$ took large account of psychological processes in our powers of knowing, of the motives of human certainty, and of the nexus between idea and reality. In objective evidence he found the supreme reason of certainty, and the sure criterion of truth. The objective reality of the object as perceived was, for him, indisputable. You could not find either activity or receptivity in nothing. To say that a thing is perceivable, and does not exist, is to affirm a contradiction (p. II I). The relation between perception and reality he held to be of the most intimate kind, so wrapped in the apprehension of the object indeed that we become certified of its existence. He deduces the reality of the object, it should be said, from the application of the principle of causality to the affective sensations, but the knowledge of 
the object is not direct or immediate, as in the case of perceptions. In the position outlined in the earlier part of this sentence, Comellas seems to follow the medieval usage of speaking of the causation of sensation by the object; the confused and perverted medieval meanings of the phrase species sensibilis in that connection did so much to obscure the apprehension of sensation as a mental fact, that Comellas had done better, I think, to avoid causal emphasis, and to extricate the mental fact of sensation from physical, and set it in psychological associations. In the latter part of the sentence, the position of Comellas is much in accord with that of Maher, who says that "a sensation is in itself an elementary mode of consciousness of a cognitional character" (Psychology, p. 46). On the question of sensation, Comellas was largely influenced by the scholastic philosophy. Thus he held that we perceive sensible objects only by touch and sight, the other senses being affective, and by them we experience only a subjective affection, caused by the objects (p. III).

Thought is one thing, says Comellas, the proposition "I think" is another (p. 237). He treats the truth and reality of knowledge of the outer world, by means of apprehension, as absolute and indefectible, but the truth and exactitude in the other case, where the data of consciousness are concerned, he ranges under the formula "I think" as a mode of locution more or less accurate-in fact, secondary and derivative. There seems to be some lack of clear discrimination about his treatment here. There may, no doubt, be error or inadequate apprehension when principles come to be applied, and opinion comes into play, but the function of reason in judgments should not be overlooked, nor should the fact be forgotten that there are both self-evident moral axioms, and self-evident and necessary truths of reason or intellect. And self-evidence, it has been said, "is really the only possible ultimate test of truth, and 
must be accepted under pain of complete intellectual paralysis. It is incapable of demonstration, since it depends on nothing else" (St. George Mivart, Elements of Science, p. 38I). Neither in the case of self-evident truths of intellect, nor of self-evident and necessary moral truths or principles, can it be satisfactory to talk of secondary and derivative, in the language of Comellas, since they assume a character necessary, universal, absolute. This, of course, does not supersede, in the case of necessary moral truths, the need for moral training and development, in order to eliminate error and perversion in the way we hold them, and to perfect fulfilment of the functions of conscience. Comellas seems to me to connect all certainty too much with sense-perception. But there is no pure sense in man without some act of the understanding; it is never purely ăhoyov (Aristotle, De Anima, III, 9, 2). And I hold that there are no good philosophical grounds for the idea that sense-knowledge is more valid and direct than other knowl-. edge. Comellas concludes, somewhat summarily and realistically, that the formula "I think" cannot be the point of departure for philosophy, since it does not relate to what he calls primordial knowledge. Now, of course, the formula "I think" cannot, as he rightly says, be the point of departure for philosophy, since it is but the ego reduced to the pure form of unity, but because this is true of Kant's blank form of thought or pure cogito, there was no reason why Comellas should not have better appreciated the aspects of moral certainty, the justice rendered by Kant to the moral reason, and his claims for moral value. The natural realism of Comellas seems to me to have crowded out, to too great an extent, his moralism. And so it happens that to-day we even see the emphasis of Comellas inverted by some thinkers, who make the conception of intrinsic value as found in Kant's ethics bear the weight of the whole philosophic structure. But creative idealism 
cannot, as it seems to me, be confined in its working to such a narrow moralistic basis, but must include in its purview the whole world of reality, fact, imagination, and thought. Meanwhile, the conception of intrinsic moral value as the clue to the ultimate nature of reality has not been shown capable of being carried out into anything like a valid or satisfying world-view. In such a worldview, both this moralistic procedure, and the nature-knowledge of Comellas, must find place, but neither of them in overweighted or one-sided manner.

Comellas takes the multiplicity and succession of spiritual acts to be facts or undoubted reality for consciousness, in which result he thinks the Kantian hypothesis of the subjective forms a priori of space and time to be inadmissible. He admits a correspondence between the object perceived and our idea of it, but thinks it is not absolute, and does not exhaust the reality of the object, but remains part of its content ( $p$. I54). I must remark, however, that neither does the subject exhaust itself in this reference to an object, as a fact to be equally recognized in psychology. In the case of infinite being or pure spirit, such correspondence of the concept with the real is not necessary, he thinks, since it is no case of an object perceived, but a procedure by combination of abstractions. It may correspond to a real being by deduction (he thinks it does so in the case of infinite being), or it may be merely possible being. The objective truth and reality of our knowledge Comellas firmly holds; he thinks our means of knowing are a legitimate source of truth; neither sensible representations nor consciousness-data nor abstract conceptions are, to him, the exclusive creation of our thinking activity; they are resultants of the knowing subject and of the objects which determines and informs it. $\mathrm{He}$ thinks that in man the possibility of error springs from his limitation and his liberty (p. 212). The will can determine the judg- 
ment, but may do so wrongly, as it lacks security-a good hint to voluntarists. Anyhow, limitation and liberty are the immediate source of error in man (p. 213). Perhaps Comellas was here influenced by Descartes, to whom he devotes chapters in the second and third parts of his work, for Descartes made error consist in defect or finitudeour "faculty for discerning truth from error" is "not infinite." In the discussion of error, Comellas thinks certainty involves the persuasion of the truth, but not the truth itself; certainty must justify itself at the bar of reason, to which latter it must conform. The rational motive of certainty and the criterion of truth as distinguished from error, must, he opines, be found in objective evidence, not in clear ideas as Descartes supposed, unless it be in clarity of the object as perceived or seen. When discussing the view of Balmez, of which he is somewhat critical (p. 223), he sums up his doctrine on the criterion of truth in the formula: "The evident is true" ("Lo evidente es verdadero," p. 222). This principle of evidence. Comellas insists, "comprehends all things evident, be they classes, or propositions, or facts, or substances, or acci. dents known by act of vision" (p. 222). What Comellas is, I think, really trying to bring out, albeit not so cleverly as might be done, is, that certainty is the concern of all knowledge, and that in all certainty, whether of what is external or internal, there is a real object; but he does not bring out, with sufficient clearness, that, while the general form of certainty is the same in all knowledge, the variant forms of certainty - mathematical, logical, scientific, moral, spiritual-are due to the differences in the matter involved. Comellas disposes somewhat lightly of the objection to his position that the object perceived has reality of being, by saying that, in the case of illusions and hallucinations, there is only sensitive appearance, not a perception properly so called. In all such cases of mere appearance, there is "no 
evidence or objective perception" (p. 229). What he defends is "the truth of the evident, the perceived or seen. but not of things apparent." False or imaginary appearances presuppose "the truth of the evident, of the perceived or seen" (p. 230). Earlier, he has insisted on the principle "the perceived is true" (p. 225) as like unto what he had said of "the evident," though he admits that, strictly taken, evidence and perception must be distinguished. Comellas, in all this somewhat hard realism, does little, it must be said, in the interest of the flow of free ideas, and the unifying of the perceptual data. It is evident that Comellas has not a little in common with what Professor Sidgwick called "the earnest, patient, lucid, and discerning intellect" of the Scottish philosopher Reid (Mind, 1895), to whom Comellas devotes a chapter in the third part of his work. There are some interesting differences, no doubt, but on these we need not now go out of our way to dwell. It must suffice to say that, though Comellas thinks we have means enough to distinguish the truth from error, he does not think we can fully reach the scientific ideal.

III.

Lastly, there are the critiques of Comellas on philosophical systems. These I have thought it desirable to place in a third section by themselves. But it should be observed that they belong mainly to the third "book" or division of the work of Comellas, which deals with the synthesis of the real with the ideal in twenty-five chapters. The critiques are introduced by half a dozen chapters on subjects like truth, error, evidence, certainty, and appearance, and I have spoken of those points in them which I wished to notice under the critical problem, as the most appropriate place. But it is in reference to the principles and criteria in them that the philosophical systems are examined and discussed by Comellas. The critiques are, it must be said, 
fragmentary, not exhaustive, but the critical work in them was done with scrupulous care and fairness, giving in footnotes the ipsissima verba of the thinkers concerned, whether German, French, or English, whenever necessary. Among the subjects of his critiques are, the methodical doubt of Descartes; the teachings of Reid, of Balmez, of Jacobi, of Lamennais; the skepticism of Kant, the rela.. tivism of Hamilton, Comte, and Spencer. Aristotle, Carneades, and Sextus Empiricus, have some attention, too. Some discussion of Plato and Aristotle, and also some treatment of Hartmann's philosophy of the unconscious, had already been given in the first "book." The pessimism of Schopenhauer; the eclecticism of Cousin; the metaphysical ideas of Krause; the views of Mill on induction and the nature of axioms, had all received handling in "book" second. Comellas, in his treatment of the systems, seeks to find in them confirmation of his own criterion of the true. I shall only speak of some points which seem to me of present-day interest.

Sextus Empiricus is repeatedly referred to by Comellas in connection with skepticism, a subject to which he devotes much attention. Comellas quotes (p. 305) from the Pyrrhonic Institutes of Sextus, wherein he says that those who think the skeptics deny phenomena do not understand their doctrines. Sextus says they do not reject things which by the impression they make upon our minds induce in us an irresistible assent. Such are phenomena. But when we examine whether the object is as it appears, we concede that it appears, but doubt whether it exists in the manner that is affirmed. Thus we concede, says Sextus, that honey has a sweet taste, because we feel sweetness, but nevertheless doubt that honey is sweet, according to the dictate of reason. With such teachings of Sextus, Comellas connects the teachings of Kant concerning the phenomenal and the noumenal, pursuing in a critical man- 
ner Kant's denial of the possibility of knowing things-inthemselves (pp. 305-3I5). He further quotes Sextus, who says that the skeptic does not employ the expressions of doubt in an absolute sense; he neither says that "all things are false," nor that "nothing is true," without recognizing that each of these statements has its own falsity. Sextus speaks similarly in his work directed against the dogmatists, and entitled Adversus Mathematicos. The affirmation of universal doubt thus goes united to doubt of that affirmation itself ( $p .309$ ). In this connection I would observe that doubt itself rests on certitude, and that, to put the whole matter more explicitly, absolute skepticism is really self-contradictory.

Comellas points out that, in the seventh book of this latter work, Sextus holds that no firm seat can be found for the negative doctrine that there exists no criterion of the truth, since to the reasons advanced for that position others equally probable can be opposed. Firmly to suspend all assent is the conclusion he reaches (pp. 308-309). Comellas also cites the passage from the eighth book of the same work in which Sextus urges against the dogmatists that, to hold that to know the truth of a thing involves necessary, infinite, and impossible suppositions, would mean that one could not with certainty know the truth of anything (p. 309). Thus there and elsewhere Comellas thinks there are indications in Sextus which point to the need of some certainty. Indeed, later, Comellas finds that Sextus at times inclines to certainty in all three moments, the empirical, the abstractive, and the deductive. This would detach him from the position of the skeptic, viewed as one "holding no form of creed but contemplating all." Ritter says that, in all this, Sextus does not give "his exposition of the skeptical doctrine as anything new, but invariably speaks in the name of his school" (History of Ancient Philosophy, Vol. IV, p. 273). It has seemed to me more 
important to dwell on the points connected with Sextus, both because they are well chosen by Comellas, and a good edition of Sextus Empiricus still remains a desideratum, and because "the skepticism which prevailed in Europe from the beginning of the sixteenth to about the close of the eighteenth century drew its inspiration, its principles, and its methods, largely from the writings of Sextus" (R. Flint, Agnosticism, p. 95).

As to Descartes, Comellas is critical of what he considers his subjective and skeptical tendency. But in his famus axiom, Cogito ergo sum, Comellas says Descartes expressly excludes from doubt his own existence because contained in his thought, and "thought," for Descartes, comprehends, he says, all the acts perceived by consciousness, save those which are by means of the bodily organism. Under "thought," moreover, are included, not only understanding, willing, and imagining, but also feeling. No doubt, the principle had a subjective and personal significance for Descartes, but it was, I think, rather meant, through the involved perpetual presence of thought, as a refuge or defense against skepticism, when, in the Method, for example, he says, "The 'I,' the mind by which I am, is wholly distinct from the body, and is even more easily known than the latter; although the latter were not, it would still continue all that it is." Descartes points out that his Cogito ergo sum is not a syllogism, but rests on a simple intuition of the mind (simplici mentis intuitu). And one need hardly say that any real doubt of our own existence would mean mental paralysis. Comellas objects that Descartes, in his discussion, confounds conception and vision: he says Descartes speaks of vision, which is a fundamental act, and then passes on to speak of conception, which is derived from it. Comellas at some length criticizes Descartes's psychology on other matters; he thinks Descartes fails to distinguish apprehension of the object 
from the mental expression of it. For my own part, I doubt whether the famous axiom of Descartes is so absolute as is commonly supposed; and the possibility of its conclusion depends on the truth and certainty of our intel. lectual operations. In making the "I think" involve and express the "I am," the axiom seems to become, in some real sort, a petitio principii. It seems to me noteworthy that Augustine and Aquinas had already used it in principle-the latter expressing it very clearly in his own way, and in a relative sense-but they held to self-consciousness as primitive indubitable fact. Yet Descartes is generally spoken of as if he were the first that ever entered the truth here, when what he did seems rather to have been to give it new, distinct formulation. It may be allowed, I think, that the axiom brings out that conscious personality is involved in every mental act.

In treating of the Spanish philosopher Balmez, whom I have dealt with elsewhere (as indicated at the beginning of this article), Comellas properly notes the influence on him of Descartes in respect of subjective tendency, and the influence of the Scottish school, as to the grounding of certainty in assent through irresistible inclination.

Comellas regards Reid and Jacobi as occupying similar positions on the principle of certainty. This Reid found in instinct or irresistible inclination, so emphasizing the "primary instincts of nature," and undervaluing the reflective reason; Jacobi found it in feeling, for to him reality can only be believed in and felt, not known. In both cases, the principle consisted in something distinct from knowledge. Jacobi's basis in feeling, Comellas thinks, is a weak one for the grounding of science (p. 286). He thinks like faults attach to their systems; they disavow, in part, the harmony of the universe; and they do not provide adequate safeguards against skepticism. While these general conclusions of Comellas are interesting, I add a few words for 
the sake of clearness. Reid and Jacobi were alike in holding an immediate knowledge before all mediate knowledge, before all inference, and all fixed and fundamental truths. Reid found a place for self-evident and intuitive truths. "There is no searching for evidence; no weighing of arguments; the proposition is not deduced or inferred from another; it has the light of truth in itself, and has no occasion to borrow it from another." He distinguished necessary from contingent truths. Though his philosophical analysis was defective, his philosophy was yet a safeguard against subjective phenomenalism. Jacobi developed his immediate knowing, which is feeling, into the two forms of perception and reason, the former for the sensuous, the latter for the supersensuous. Not through thought, but through feeling, does the actual assert itself, for Jacobi. in human consciousness. Jacobi is not like Reid, when, for him, there is no reality outside consciousness, but he reminds us of Reid in his insistences on immediate perception. They both fought for the rights of immediacy and of reality, but each in his own way. Comellas thinks skepticism has been shown not to have foundation enough to engender certainty of the truth (p. 323). In which connection I would recall what was well said by Dr. Edward Caird, that "the very logic by which the skeptic overthrows the dogmas of philosophy, implies that the mind possesses in itself the form and idea of truth. His deepest doubt reveals a certitude that transcends and embraces it."

Lamennais is criticized by Comellas for his advocacy of the impotence of human reason to distinguish the true, and to reach certainty, and for his impressive attempt to found a doctrine of traditionalism on skeptical bases, or, in other words, to take refuge in divine revelation. This. Comellas argues, would make the criterion of the true objective-subjective, and set it in an extrinsic order. Not only does Lamennais make divine revelation the principle 
of certainty, but, sacrificing the individual reason, he makes the common or catholic consent the means of knowing that revelation. The infallible guarantee of the primitive traditions is found by Lamennais in the human race. Divine authority is made by him the basis of the certainty of our knowledge. Common consent or collective reason is the only seal or stamp of the truth. But, in the view of Comellas, the doctrine of Lamennais has no solid foundation, since it carries no immediate evidence, nor any demonstrative force. It is impotent, he says, to reach certain knowledge of the truth, since it does not proceed from individual reason. The common consent was, to him, a begging of the question, a supposing of the very thing to be proved. The doctrine of Lamennais was, to Comellas, self-contradictory. It assumed individual reason, able to be certain of the common consent as the means of knowing the divine revelation; it did not allow individual reason to reach certainty of any particular fact, but supposed it able to be certain of so general a fact as the common consent. I will only remark that Lamennais carried his skeptical basis to an extreme that was self-destructive. If you begin by making individual reason wholly fallacious, and treat individual assent as of no value, the general consent, built on such a basis, can have no value either.

Comellas has a good chapter on the philosophy of Krause, who has attracted much attention in Spain. But Comellas objects to it as giving an excessive importance to experience, and as participating in the subjection of Fichte and the intellectual intuitionism of Schelling. His criticism is based on study, not only of Krause's own works, but also of Tiberghien's exposition of Krause (in his Introduction à la philosophie, Brussels, 1880). The final conclusions of Comellas are, that Krause's philosophy, on one side, exaggerates the powers of the human understanding by admitting a single principle of all our knowl- 
edge; and, on another side, is opposed to its full development, inasmuch as it adopts an insufficient point of departure, making the contemplation of being the fundamental principle of all knowledge, and neglecting the empirical element in its deductions. For these reasons Comellas cannot allow the philosophy of Krause the merit of the extension, or the purity, or the solidity, of science or knowledge. Still, I do not think we can forget that it had its distinct merits, not the least conspicuous of which was his fine insistence on objective morality in law and history. But it was a mistake when Krause made nature and reason or mind coordinate, instead of, like Hegel, making nature subserve the ends of reason or mind.

Comellas is critical of Cousin's eclecticism, with its claim, by this method, to reach the whole of truth. In this I need hardly now follow him, except to say that I think he took a too external view of the eclective method-as so many have done-and this has been very clearly corrected by some recent French philosophers. I think it more needful to remark that, in the view of Cousin, truth was always present in reflection, although there might enter error too. And another point, not overtaken by the limited treatment of Comellas, is the interesting distinction rased by Cousin between spontaneous and reflective intelligence, but not satisfactorily disposed of by him (see R. Flint, The Philosophy of History, pp. 46I-464).

Comellas objects to the relativity theories of Hamilton, Comte and Spencer, which he thinks experience does not favor (p. 370). Certainly it was absurd when Hamilton and Spencer thought we cannot know the object as it is in itself, on the ground that we cannot know it save as different from and yet related to the subject. Absurd, because knowledge that should not involve distinction is really impossible. The want of complete knowledge, which holds true of all reality, does not involve ignorance of all the real 
(p. 370). It is too often overlooked, I must observe, that, if the doctrine of the relativity of knowledge be true, it must be true of the doctrine of the relativity of knowledge itself. If it is, as a theory, merely relative and phenomenal, then it cannot be known to be true. But if it be held as really true-which means that some of our knowledge is absolute-then it can no longer be true to say that all our knowledge is merely relative. Knowledge is, indeed, in a proper sense, relative, but it establishes a relation between us and the absolute, whose nature is self-revealing. While skepticism, in an absolute sense, is self-destructive, its method is not without real advantages in scientific investigation, where theoretic assumptions must be tested. I think Comellas overlooks too much this aspect of the case. The impossibility of understanding the most recondite forms of being, to which Spencer refers, proves the limitation of human knowledge, but does not, in the view of Comellas, justify skepticism (p. 370). With sure knowledge of substances, acts, and real attributes, may well be reconciled, in his view, the want of unlimited knowledge. The human understanding has, in his view, the force of which these philosophers deem it destitute (p. 374). In the three moments, empirical, abstractive, and deductive, he holds (pp. 360,374) that we know things-in-themselves, and not mere appearances. I am tempted to add, in this connection, the words of a forgotten writer on ethics, "Men have always chosen skepticism before absurdity, when both are fairly before them; because skepticism, though itself the greatest absurdity, is of all others the most recondite and imposing." Comellas thinks the real world does not bear the sombre character which skepticism attributes to it. The harmony and mutual expansion obtaining, in the empiric moment of our knowledge, between man and the world's forces, and the vigor evidenced by man in the moments abstractive and deductive, are a manifestation of the ten- 
dency of the universe toward the ideal (p. 375). The universe, says Comellas, is not a dark abyss, into which the gaze of man cannot penetrate; it is, on the contrary, inundated with light, and allows itself to be scrutinized by our limited intelligence.

In conclusion, I may remark that such discussions as those of Comellas, with their stress on the objective aspects of truth and certainty, raise issues too much overlooked in modern subjective theories. To take one of the latest of these-that of Croce-truth is never static, to Croce, not even in logic, truth is faith, certainty of one's self, free development of one's inner power. But this subjective trueness of one's spirit can be no substitute for, or replacement of, the objective aspects of truth and certainty. If truth is faith, Croce's pure concepts are pure ideals, for faith is always an unfulfilled ideal, and truth is then never realized. But the science of Being, or the metaphysics, which Croce has discarded, is not to be disposed of in any such way, but remains the permanent core of all immanent evolution.

Irvine, Scotland.

JAMES LINDSAY. 